\title{
The Challenge of Long-Term Climate Change
}

\author{
K. Hasselmann, ${ }^{1,2 *}$ M. Latif, ${ }^{3}$ G. Hooss, ${ }^{4}$ C. Azar, ${ }^{5}$ O. Edenhofer ${ }^{1,6}$ C. C. Jaeger, ${ }^{1,6}$ O. M. Johannessen, ${ }^{1,7}$ \\ C. Kemfert, ${ }^{1,4}$ M. Welp, ${ }^{1,6}$ A. Wokaun ${ }^{1,8}$
}

Climate policy needs to address the multidecadal to centennial time scale of climate change. Although the realization of short-term targets is an important first step, to be effective climate policies need to be conceived as long-term programs that will achieve a gradual transition to an essentially emission-free economy on the time scale of a century. This requires a considerably broader spectrum of policy measures than the primarily market-based instruments invoked for shorter term mitigation policies. A successful climate policy must consist of a dual approach focusing on both short-term targets and long-term goals.

There is widespread consensus in the climate research community that human activities are changing the climate through the release of greenhouse gases, particularly $\mathrm{CO}_{2}$, into the atmosphere $(1,2)$. Because of the considerable inertia of the climate system - caused by the long residence times of many greenhouse gases in the atmosphere, the large heat capacity of the oceans, and the long memory of other components of the climate system, such as ice sheets and the biosphere-human modifications of the climate system through greenhouse gas emissions are likely to persist for many centuries in the absence of appropriate mitigation measures (2).

A common response to the uncertain risks of future climate change is to develop climate policy as a sequence of small steps. The Kyoto protocol, once enacted, will commit the signatories to a nominal reduction of greenhouse gas emissions by $5 \%$ between 2008 and 2012, relative to 1990 . The protocol is a historic first step toward reversing the trend of continually increasing greenhouse gas emissions and will provide valuable experience in the application of various mitigation instruments such as tradable emission permits. However, a nominal emission reduction of only $5 \%$ by a subset of the world's nations will have a negligible impact on future global warming. To avoid major long-term climate change, average per capita greenhouse gas emissions must be reduced to a small fraction of the present levels of developed countries on the time scale of a century (2).

1European Climate Forum, www.european-climateforum.net. 'Max Planck Institute for Meteorology, Hamburg, Germany. ${ }^{3}$ Institute of Marine Research, Kiel, Germany. ${ }^{4}$ Oldenburg University, Oldenburg, Germany. ${ }^{5}$ Chalmers University of Technology, Göteberg, Sweden. ${ }^{6}$ Potsdam Institute of Climate Impact Research, Potsdam, Germany. ${ }^{7}$ Nansen Environmental and Remote Sensing Center/Geophysical Institute, University of Bergen, Bergen, Norway. ${ }^{8}$ Paul Scherrer Institut, Eidgenössische Technische Hochschule, Zurich, Switzerland.

*To whom correspondence should be addressed. Email: klaus.hasselmann@dkrz.de
Such reductions cannot be achieved by simply extrapolating short-term policies but require a broader spectrum of instruments.

Most investigations (2-4) and public attention have focused on the projected climate change in this century. A potentially far more serious problem, however, is the global warming anticipated in subsequent centuries if greenhouse gas emissions continue to increase unabated (Fig. 1, left panels) (5-7). The projected temperature and sea level changes for the next millennium greatly exceed those in the next hundred years (Fig. 1, yellow boxes). If all estimated fossil fuel resources are burnt, $\mathrm{CO}_{2}$ concentrations between 1200 parts per million (ppm) (scenario $\mathrm{C}$ in Fig. 1) and 4000 ppm (scenario E in Fig. 1) are predicted in the second half of this millennium, leading to temperature increases of $4^{\circ} \mathrm{C}$ to $9^{\circ} \mathrm{C}$ and a sea level rise of 3 to $8 \mathrm{~m}$. Predictions of this magnitude are beyond the calibration ranges of climate models and must therefore be treated with caution $(8)$. However, the predicted climate change clearly far exceeds the natural climate variability $\left(\sim 1^{\circ} \mathrm{C}\right.$ to $\left.2^{\circ} \mathrm{C}\right)$ experienced in the past 10,000 years. Even if emissions are frozen at present levels, the accumulated emissions over several centuries still yield climate change on the order of the lower business-as-usual (BAU) scenario $\mathrm{C}$.

Major climate change can be avoided in the long term only by reducing global emissions to a small fraction of present levels within one or two centuries. As an example, we have computed optimal $\mathrm{CO}_{2}$ emissions paths that minimize the time-integrated sum of climate damage and mitigation costs, using an integrated assessment model consisting of a nonlinear impulse response climate model (7) coupled to an elementary economic model (9) (Fig. 1, right panels). Cost-benefit analyses depend on many controversial assumptions, such as the role of economic inertia (included in case a, ignored in case b), the impact of declining costs for new technologies, and the discount factors applied to future climate change mitigation and adaptation costs (10-14). However, the resultant longterm climate change is insensitive to the details of the optimal emission path (compare curves a and $b$ ), provided the emissions are sufficiently reduced. Because of the long residence time of $\mathrm{CO}_{2}$ in the atmosphere $(>100$ years), the climatic response is governed by the cumulative $\mathrm{CO}_{2}$ emissions rather than by the detailed path.

The impact of the Kyoto agreement $(\mathrm{k}$ in Fig. 1, right panels) is hardly discernible on the millennial time scale, suggesting that the Kyoto debate should focus on the long-term implications of the protocol rather than on its short-term effectiveness. The Kyoto targets may not be met by some countries and may be exceeded by others. Important in either case is that the Kyoto policy is accompanied by measures that ensure continuing reductions in subsequent decades.

Because of the 10-year horizon of the Kyoto protocol, climate policy has tended to focus on promoting mitigation technologies that are currently most cost-effective, such as wind energy, biomass fuels, fuel switching from coal and oil to gas, and improved energy efficiency in transportation, buildings, and industry. In the short to medium term, the combined mitigation potential of these technologies is substantial: It has been estimated that, if fully implemented, they could halve global greenhouse gas emissions relative to the BAU level within two decades (4). The market-based instruments (such as tradable emission permits and tax incentives) used to meet the more modest 5\% Kyoto reduction targets will accelerate the penetration of these technologies into the marketplace but will be inadequate to realize the full potential of these technologies.

Yet, even if forcefully implemented, currently available low-cost technologies have limited capacity for substantial global emission reduction and will not be able to counter the rising emissions projected for the long term. Future emissions will be driven mainly by the expanding populations of the developing world, which strive to achieve the same living standards as the industrial countries. An emissions reduction of $50 \%$ applied to a projected BAU increase in this century by a factor of four (2-4) still leads to a doubling of emissions, far from the long-term target of near-zero emissions. Furthermore, the mitigation costs for today's technologies are estimated to rise rapidly if per capita emissions are reduced by more than half (4). Thus, although the Kyoto protocol will 
boost technologies that are cost-effective in the short term, further emission reductions in the post-Kyoto period could be limited by prohibitive costs. Without affordable new technologies capable of higher global emission reductions, stricter emission reduction targets will be considered impossible to meet and will not be adopted.

Although no such technology is yet economically competitive, there exist many promising candidates $(15,16)$, ranging from solar thermal or photovoltaic energy - in combination with hydrogen technology - to carbon sequestration in geological formations or the ocean (17-20), advanced nuclear fission, and nuclear fusion $(4,15,16)$. Which technology, or mix of technologies, will ultimately prove most cost-effective cannot be predicted. We will need to accept these uncertainties and support a number of competing technologies in order to have available several commercially viable alternatives when the large-scale transition to low-emission technologies becomes more urgent.

Although short-term climate policy can be formulated in terms of emission targets and implemented with instruments that internalize the costs incurred by climate change ("polluterpays principle"), long-term climate policy will require a broader spectrum of measures extending well beyond the traditional horizon of government policies or business investment decisions. The entry of new technologies into the marketplace depends on multiple incentives and feedbacks, including private investments; government investments in infrastructure and subsidies for pilot plants; protected niche markets; and changes in consumer preferences and lifestyles (21-23). Climate is a public good that demands communal action for its protection, including the involvement of citizens and institutions such as the media that shape long-term public attitudes. Self-interest alone will not motivate businesses and the public to change established practices and behavioral patterns. The goal of long-term climate policy must be to influence business investments, research, education, and public perceptions such that stringent emission-reduction targets - although not attainable today-become acceptable at a later time.

Although major changes are necessary, the long time scales of the climate system allow a gradual transition $(24,25)$. Estimated costs to halve global emissions range from $\sim 1$ to $3 \%$ of gross domestic product (GDP) (4), similar to the annual GDP growth rate in many countries. Thus, implementation of an effective climate policy over a time period of, say, 50 years would delay economic growth by only about a year over the same period (26). This appears to be an acceptable price for avoiding the risks of climate change. However, because the global political-economic system exhibits considerable inertia, a transition to a sustainable climate can be achieved without major socioeconomic dislocations only if the introduction of appropriate measures addressing the long-term mitigation goals is not delayed.

Science can assist the development of long-term climate policies by providing detailed analyses of the technological options and their implications for national economies and global development. The Intergovernmental Panel on Climate Change (IPCC) has played a pivotal role in the climate debate by presenting authoritative reviews of the state of science and on climate change impact, mitigation, and policy. Similar expertise should be made available to climate negotiators in the form of timely analyses of the implications of alternative climate policy regimes for the individual signatories of the United Nations Framework Convention on Climate Change. Although binding long-term commitments cannot be expected from governments, declarations of long-term policy goals and visible actions to achieve these goals are essential for the investment plans of businesses, particularly for energy technologies characterized by long capital lifetimes. A long-term perspective is equally important for the public, who must understand and support the policies. Binding commitments to meet short-term emission-reduction targets must therefore go hand in hand with clearly defined strategies to achieve substantially more stringent reductions in the longer term. 


\section{TRAGEDY OF THE COMMONS?}

\section{References and Notes}

1. T. P. Barnett et al., Bull. Am. Meteor. Soc. 80, 2631 (1999).

2. Intergovernmental Panel on Climate Change, Climate Change 2001, Working Group 1: The Scientific Basis, J. T. Houghton et al., Eds. (Cambridge University Press, 2001).

3. IPCC, Climate Change 2001, Working Group 2 Impacts, Adaptation, and Vulnerability, J. J. McCarthy et al., Eds. (Cambridge University Press, 2001).

4. IPCC, Climate Change 2001, Working Group 3: Mitigation, B. Metz et al., Eds. (Cambridge University Press, 2001).

5. W. R. Cline, The Economics of Global Warming (Institute for International Economics, Washington, DC 1992).

6. T. J. Crowley, K-Y Kim, Geophys. Res. Lett. 22, 933 (1995).

7. G. R. Hooss et al., Clim. Dyn. 18, 189 (2001).

8. The uncertainties of climate predictions are estimated to be $\sim 50 \%$, excluding instabilities of the climate system that could yield substantially larger changes, for example, through the collapse of the
Gulf Stream and deep ocean circulation system, a break-off of the West Antarctic ice sheet, or the release of methane presently frozen in permafrost regions.

9. K. Hasselmann et al., Climatic Change 37, 345 (1997)

10. W. D. Nordhaus, Science 294, 1283 (2001)

11. P. G. Brown, Climatic Change 37, 329 (1997).

12. G. Heal, Climatic Change 37, 335 (1997)

13. W. D. Nordhaus, Climatic Change 37, 315 (1997)

14. K. Hasselmann, Climatic Change 41, 333 (1999).

15. J. Goldemberg, Ed. World Energy Assessment (2000): Energy and the Challenge of Sustainability (United Nations Development Programme, United Nations Department of Economics and Social Affairs, World Energy Council, New York, 2001).

16. M. I. Hoffert et al., Science 298, 981 (2002).

17. B. P. Eliassen et al., Eds., Greenhouse Gas Control Technologies (Pergamon, Amsterdam, 1999).

18. K. S. Lackner, Science 300, 167 (2003).

19. P. G. Brewer et al., Science 284, 943 (1999).

20. H. Drange et al., Geophys. Res. Lett. 28, 2637 (2001).

21. M. Haduong et al., Nature 389, 270 (1997).

22. O. Edenhofer et al., in preparation.
23. Examples are tradable renewable energy permits (27) and long-term policies in tradable emission permits $(28,29)$.

24. J. Alcamo, E. Kreileman, Global Environ. Change 6, 305 (1996).

25. B. C. O'Neill, M. Oppenheimer, Science 296, 1971 (2002).

26. C. Azar, S. H. Schneider, Ecol. Econ. 42, 73 (2002).

27. D. Barry, Ecol. Econ. 42, 369 (2002).

28. S. C. Peck, T. J. Teisberg, in Risk and Uncertainty in Environmental and Resource Economics, J. Wesseler, H-P Weikard, Eds. (Edward Elgar, United Kingdom, in press), chap. 9.

29. M. Leimbach, Energy Policy 31, 1033 (2003).

30. The views expressed in this article evolved from discussions with members and guests of the European Climate Forum (ECF). We acknowledge constructive comments from G. Berz, C. Carraro, B. Eliasson, J. Engelhard J. Gretz, B. Hare, J.-C. Hourcade, M. Hulme, M. Mcfarland, N. Otter, H.-J. Schellnhuber, S. Singer, and S. C. Peck. However, ECF does not endorse specific views expressed by its members, and this article does not represent an ECF consensus view.

Web Resources

www.sciencemag.org/cgi/content/full/302/5652/1923/ DC1 